\title{
Mass SARS-CoV-2 serological screening for the Principality of Andorra
}

Cristina Royo-Cebrecos ( $\square$ lacrisroyo@gmail.com )

Hospital Nostra Senyora Meritxell https://orcid.org/0000-0003-2554-4656

David Vilanova

Genomictales

Joel López

Andorra Innovation Hub

Vanessa Arroyo

Andorra Innovation Hub

Guillem Francisco

Andorra Innovation Hub

Marc Pons

Andorra Innovation Hub

Mireia G. Carrasco

Andorran Ministry of Health,

Josep M. Piqué

Andorra Health Services

Sergi Sanz

ISGlobal https://orcid.org/0000-0001-5010-4527

Carlota Dobaño

ISGlobal https://orcid.org/0000-0002-6751-4060

Alberto García-Basteiro

ISGlobal https://orcid.org/0000-0002-2038-5505

\section{Article}

Keywords: SARS-CoV-2, Andorra, serological testing

Posted Date: December 4th, 2020

DOI: https://doi.org/10.21203/rs.3.rs-119323/v1

License: (c) (1) This work is licensed under a Creative Commons Attribution 4.0 International License. Read Full License 


\section{Abstract}

Andorra is a small country located in the Pyrenees attracting millions of visitors, mainly for ski tourism. We estimated SARS-CoV-2 seroprevalence in the entire country by universal serological testing. From 428 May, 2020 two cross sectional serological surveys were conducted using a rapid serological test (nCOV IgG/lgM). 72,964 inhabitants (96.1\% of the population) participated. Overall seroprevalence was $11.0 \%$. The odds of being seropositive was higher among seasonal workers (OR 1.87; 95\% $\mathrm{Cl} 1.57-2.23$ ), students (OR 1.64; 95\% Cl 1.48-1.82) or in the population living in La Massana region (OR 2.65; $95 \% \mathrm{Cl}$ 2.43-2.89). A higher seroprevalence was observed in those familiar nuclei with greater numbers of cohabitants: $18 \%$ in families with 6 household members or more; $13 \%$ in medium size families $(3 / 4 / 5$ people) and $12 \%$ in small size ( 1 to 2 people) nuclei $(p<0.001)$. Seasonal workers, students and inhabitants based in ski-related areas presented a higher seroprevalence. Mass antibody screening allows to identify infection hotspots and should contribute to the design of tailored interventions to prevent SARS-CoV-2 transmission.

\section{Introduction}

The ongoing pandemic of COVID-19, caused by severe acute respiratory syndrome coronavirus 2 (SARSCoV-2) has affected almost every country in the world. ${ }^{1,2}$ Despite the rapid spread of the disease, the reported number of cases in many territories is just a proportion of the real number, given the limited diagnostic capacity in many settings, the lack of available and consistent diagnostic protocols during the initial phases of the pandemic or the absence of plans to produce or import diagnostic tests and reagents, among others. A robust screening program for early detection and isolation of SARS-CoV-2 positive individuals is crucial to reduce the transmission of the virus. ${ }^{3}$ In addition, the detection of antibodies against SARS-CoV-2 at a population level can provide a minimum estimate of people who have experienced the infection and thus guide decision-making if, for example, there is a good correlation between antibody detection and protection from re-infection. ${ }^{4-8}$ Likewise, as we face new waves of the epidemic, ${ }^{9}$ seroprevalence studies can contribute to identify high risk population groups who could benefit from tailored preventive strategies.

Andorra is a small country located in the Pyrenean mountains, with about 78,000 inhabitants. It is world famous as a tourist destination attracting over 8 million visitors annually. Located between France and Spain, two of the most affected countries by COVID-19 in Europe, Andorra has also been hardly hit by this pandemic with a total of 2110 notified cases, and a mortality rate of 686 per million population as of October 4th, 2020. ${ }^{10}$ Given these exceptional circumstances, Andorra offers an ideal and a unique setting to evaluate the feasibility of a serological mass screening program on its entire population. This would provide precise figures on the proportion of the population who have been infected by SARS-CoV-2, and therefore, contribute to the design of control strategies adapted to the Andorran setting.

Most seroprevalence studies performed in other settings have included specific high-risk groups or randomly-selected participants which exclude certain population groups, such as ill or quarantined 
people, or institutionalized individuals, among others. ${ }^{11-21}$ Thus, their results might not accurately reflect the actual seroprevalence in the population. To date, no studies have been published attempting to estimate SARS-CoV-2 seroprevalence in a country by universal serological testing.

The aim of this study is to estimate the seroprevalence for SARS-CoV-2 in the population of Andorra under a lockdown environment and strict border restrictions after the first two COVID-19 cases were detected. The secondary objectives are a) to estimate the seroconversion patterns over a 15-day period in a confined population, b) to identify high-risk population groups, and c) to estimate the seroprevalence at household level.

\section{Methods}

\section{Study design and population}

We conducted a two-phase screening study on the entire population in Andorra above the age of 2 who voluntarily signed the informed consent. Beyond Andorran citizens, we also included registered crossborder workers. The only exclusion criterion was the refusal to provide the signed informed consent.

The study included two cross-sectional serological surveys using a rapid serological test on a finger prick blood sample. The first survey (day 0-10) began on 4 May, 2020, and the second started 2 weeks after the end of the first one (day 14-28). The objectives of the second survey were two-fold: a) to detect seroconversion in participants who might have been infected at the time of the first survey, and $b$ ) to account for indeterminate results or potential false negative results of the test in the first survey.

\section{Timeline of public health measures around the study period}

Andorra was locked down on March 13th, 2020 and a voluntary quarantine was requested to the entire population. The country borders were not closed, but transit in neighboring countries was heavily restricted and controlled. Only personnel working in the provision of basic services such as groceries stores, pharmacies, special security forces and health workers who provide service at Hospital Nostra Senyora de Meritxell (the main referral hospital facility in the country) were allowed to crossed the border. On May 18th, 2020, around 30\% of the country's activity was restarted. Sports activities such as walking and running were allowed on alternate days and at specific times of the day. On June 1st, the entire country's economic activities and services resumed with the end of lockdown.

\section{Study procedures}

Participants were invited to participate through television and social media advertisements. Registration for the test was performed online through the website (http://coronavirus.govern.ad/), designed for providing information about the pandemic as well as monitoring COVID-19 related symptoms in affected patients. 
To perform both surveys, 59 drive-through or walk-through checkpoints called 'StopLabs' were enabled across the country with 1500 volunteers participating in its setup. During sample collection, public officials collected patient's data and registered them into an electronic database. Finger prick samples were collected by qualified health care workers. "Drive-thru" testing took around 5 minutes per person. The test result was available within 15 minutes and the results were uploaded into the database. People with reduced mobility and from social health centers were screened through mobile units at their households. Within twenty-four hours, all participants received the results, via a text message. Individuals testing positive for IgM received a message with the recommendation to contact the referring general practitioner who would then assess the need for a PCR test. Clinical decisions derived from testing, such as isolation or quarantine, followed national guidelines (Supplementary Table 1 and Fig. 1). At the end of the two tests, tested people had access to their results, on the web platform using a personal identifier.

\section{Serological test}

We used the Livzon $\circledast$ rapid test, a diagnostic kit for $\operatorname{lgM} / \lg G$ antibody detection against SARS-Cov-2 based on a lateral flow assay (nCOV 2019 lgG/IgM- Zhuhai Livzon Diagnostics, Inc. - IgM and IgG kits, Colloidal gold). The test was selected based on a list of recommended tests from FIND (https://www.finddx.org/covid-19/sarscov2-eval-immuno/). The kit is CFDA/NMPA approved (China's State Food and Drug Administration/ National Medical Products Administration), and it detects IgM and IgG on the same test providing a maximum combined sensitivity and specificity of $90.6 \%$ and $99.2 \%$, respectively (according to the manufacturer). Prior to its use in the surveys, the test was evaluated in 87 COVID-19 patients from Nostra Senyora de Meritxell Hospital. Samples used for assay validation came from 48 symptomatic individuals diagnosed of COVID-19 (cases) who had tested positive by SARS-CoV-2 PCR and 48 healthy donors who served as controls (PCR negative). Among cases, serum samples were obtained 10 days or more after symptoms onset. We found a specificity of $100 \%(\mathrm{Cl} 95 \% ; 0.95-1)$ and sensitivity of $92 \%$ ( $\mathrm{Cl} 95 \% ; 0.84-0.96)$. A second evaluation of the test was performed at the ISGlobal laboratory (Barcelona, Spain) in August 2020 following FIND (Foundation for Innovative Diagnostics) recommendations. The study tested 119 plasma/serum samples from individuals with a confirmed past/current diagnosis of COVID-19, including 109 PCR-confirmed positive samples, and 129 prepandemic negative controls. We found that the combined sensitivity (IgM-lgG) ranged from $0.72-0.78$ depending on the days since symptoms onset ( 7 or 14 days) $0.71-0.81$ when positive samples were PCRconfirmed (Supplementary table 1). Specificity ranged from 0.98-0.99.

\section{Statistical analysis}

Seroprevalence of antibodies against SARS-CoV-2 were calculated as proportions with $95 \% \mathrm{Cl}$. Given the moderate sensitivity and high specificity of the test in our two-step validation process, the numerator for the overall seroprevalence was the number of individuals who had a positive result of IgG and/or IgM at any of the two surveys. The denominator was the population estimates of the Andorra's Government Department of Statistics, as of April 1st, 2020. ${ }^{22}$ Consequently, to calculate the overall proportion of seronegative individuals we used a numerator which includes those participants with a negative result in 
both surveys, an inconclusive result and one inconclusive result, or with just one negative result if the individual only participated in one survey. Seroconversion was defined as a transition of the test results (IgM or $\mathrm{IgG}$ ) from negative to positive from the first to the second survey. Conversely, seroreversion was defined as a transition of the test results for IgG or IgM against SARS-CoV-2 from positive to negative results. Inconclusive results were those that could not be interpreted correctly. The asymptomatic proportion was calculated as the percentage of people with initial infection (lgM+ / lgG-), advanced infection (lgM+ / IgG+) or resolved infection (lgM- / IgG+) who did not report symptoms from the beginning of the epidemic until the study concluded.

Seasonal workers were defined as those who worked only seasonally in the country during the period from October to May and provide services mostly related to ski resorts activities (97\%). ${ }^{21}$

Spatial analysis included the seven parish or territories in which the Principality of Andorra is administratively divided. The descriptive analysis of the main socio-demographic variables is reported with absolute frequencies and percentages for categorical variables and with mean and standard deviation or interquartile range for quantitative variables, as appropriate. We tested the association between variables with the Chi-square or Fisher's exact test (for categorical variables) and T Student test (for continuous quantitative variables). Univariable and multivariable logistic regression models (MLM) were run to evaluate factors associated with seroprevalence of antibodies against SARS-CoV-2. For the variables to be included in the MLM model, we used a stepwise selection, starting with the full model, and using a $p$ value of 0.10 for removal and 0.05 for addition of variables.

The significance level was set at 0.05 , and the analysis was carried out using the statistical software Stata v16.1 (College Station, TX: StataCorp LLC) and R studio version R-3.5.1.

\section{Ethical issues}

The protocol of the study was approved by the relevant Andorran regulatory agencies and the local Research Ethics Committee. Participation in the study was entirely voluntary. The Institutional Review Board of the Servei Andorrà Atenció Sanitaria (SAAS) approved the study (register number 0720). This study was supported and approved by the Andorran government.

\section{Results}

Of a total of 75,926 inhabitants in Andorra ( $\geq 2$ years old), 70,389 (92.7\%) participated in the first survey and $63,708(84.0 \%)$ in the second one. A total of 63,603 (83.9\%) completed the two surveys (Figure 1). Among the 70,494 (92.8\%) who participated in at least one of the surveys, the mean age was 40.4 (SD: 20.0 ) years old, $32,204(50.6 \%)$ were male, and the region that contributed with more participants was Andorra la Vella with $21,102(29 \%)$ participants. The most frequent age group among study participants was the $40-49$ years old (19.5\% of all participants) (Table 1$)$. There was a higher frequency of seasonal workers in regions related to skiing activities: $66.6 \%$ of seasonal workers resided in the region of Canillo/Encamp, and 16.5\% in the regions of La Massana/Ordino (Supplementary Table 4). 
The seroprevalence in the first survey, conducted under a strict population lockdown, was $9.7 \%(95 \% \mathrm{Cl}$ 9.5-9.9) while the seroprevalence of the second survey, conducted under a partial population confinement, was $8.5 \%$ (95\% $\mathrm{Cl} 8.3-8.7)$. The overall seroprevalence (considering seropositivity in either survey) was $11.0 \%$ (95\% Cl 10.8-11-2) (Table 2). A total of 61,639 (87.4\%) participants were negative in both surveys, $117(0.2 \%)$ participants had an inconclusive result in the first survey, $79(0.1 \%)$ in the second survey and none in the two surveys. Between the first and the second cross-sectional survey, a total of 2,066 people $(2.8 \%)$ seroconverted and 2,612 people (3.6\%) seroreverted.

Among participants that tested positive, the mean age was 43.2 years in both surveys (SD: 20.3 and SD: 20.5 in first and second survey respectively). Most participants were asymptomatic at the time of the surveys, only $1,972 / 66,753(2.9 \%)$ reported symptoms in the first survey and $857 / 60,211(1.4 \%)$ in the second one. Among participants with at least one positive antibody isotype, the most frequently observed pattern was IgM+/lgG- (3.6\%) which, according to our algorithm, was considered to be due to a recent acute infection (Supplementary Table 3).

A total of 4,364/73,265 (6.0\%) participants had been tested by RT-PCR prior to the survey. Among those who had a previous positive RT-PCR, 305/378 (78.0\%) were seropositive in the first survey. After the second survey and following the national algorithm (Supplementary Figure 1), a total of 1,518 PCR tests were performed, of which 23 were positive.

\section{Seroprevalence in different population groups (univariable analysis).}

Seroprevalences in different population groups are reported in table 2. No differences were observed by sex $(11.4 \%$ of seroprevalence in females and $11.3 \%$ in males, $p=0.06)$. The most seroprevalent age groups were those over 90 years old (15.2\%) and 80-89 (13.8\%), followed by adults $50-59(13.6 \%)$ and adolescents aged 10-19 (13.7\%).

Among health care workers ( $n=2,167$ (3.1\%) of all participants), seroprevalence was $10.4 \%$. Only 68 (3.1\% of 2,193 health care workers) of all health care workers reported having COVID-19 compatible symptoms before the first survey. Seasonal workers presented higher seroprevalence in the first survey than the general population $13.3 \%$ vs $9.7 \%(p<0.0001)$.

Figure 2 shows the spatial distribution of the seroprevalence in Andorra, per parish. The overall highest seroprevalence was observed in La Massana (17.8\%), Sant Julià de Lorià (14.2\%) and EscaldesEngordany (11.4\%). The regional distribution by seasonal workers is detailed in Supplementary, table 3 and figure 2 .

\section{Multivariable analysis of factors affecting seroprevalence}

The odds of being seropositive were higher in elderly participants age above 90 years (OR: $1.61,95 \% \mathrm{Cl}$ 1.31-2.31, $\mathrm{p}<0.0001$ ), than in 80-89 years (OR: $1.34,95 \% \mathrm{Cl} 1.11-1.63, \mathrm{p}<0.0001$ ) and $50-59$ years (OR: $1.18,95 \% \mathrm{Cl} 1.18-1.48, \mathrm{p}<0.0001)$. Participants who presented any COVID-19 related symptoms, especially in the first survey, presented higher odds (OR: 1.99, 95\% Cl 1.71-2.31; $p<0.0001$ ) of being 
seropositive than asymptomatic participants. The occupations more strongly associated with a seropositive result were seasonal workers (OR 1.87; 95\% Cl 1.57- 2.23, $\mathrm{p}<0.0001$ ) and students (OR 1.64; $95 \% \mathrm{Cl} 1.48-1.82 \mathrm{p}<0.0001)$. The parishes with higher odds were La Massana (OR 2.65; $95 \% \mathrm{Cl} 2.43-$ 2.89) and Sant Julià de Lorià (OR 1.84; $95 \% \mathrm{Cl} 1.68-2.02)$ followed by Ordino (OR: 1.47, 95\% Cl 1.30-1.67), all with $p<0.001$, on the multivariable analysis (Table 3 ).

\section{Household level seroprevalence}

The median household size was 3 people (95\% Cl: 2.0-3.0). Higher mean seroprevalence was observed in households with a greater number of cohabitants, being highest in those with 6 or more people (18\%), followed by those with medium size ( 4 to 5 people) (13\%) and small size (1 to 2 people) (12\%), with a $p<0.001$. The proportion of seroconverters increased in larger households, from $3.5 \%$ in small households, to $7.1 \%$ in medium and $14.1 \%$ in large households, with a $p<0.0001$. Table 4 ).

\section{Discussion}

This is the first seroprevalence study universally testing the entire population of a country and the largest of its kind worldwide. With 70,624 voluntary participants, the study covered $91 \%$ of the population of Andorra. ${ }^{22}$ The overall seroprevalence was $11.0 \%$ in May 2020, therefore a considerable portion of the population appeared to have been exposed to the virus during the initial peak. The detection of both IgM and IgG allowed us to identify acute (lgM+/lgG-) or subacute (lgM+/lgG+) infections and led to public health recommendations: isolation of the positively tested people and quarantine of their contacts to prevent the spread of virus, at a time when the country was at an early stage of relaxation of lockdown measures. A peculiarity of Andorra is the high presence of ski-related tourists and seasonal workers during the first wave of the pandemic. We observed a high seroprevalence among seasonal workers (> $95 \%$ working in ski-related activities) and areas located near to the main ski resorts, such as La Massana, Ordino and Canillo.

We observed an overall seroprevalence of $11.0 \%$, higher than other studies conducted at around the same time in neighboring countries. ${ }^{11-20}$ This might be due to the population influx from areas with high seroprevalence in Spain or France, who travel frequently to Andorra. In a study conducted in the Spanish population, ${ }^{11}$ the overall seroprevalence during the first fortnight of May was $5 \%$ (95\% Cl 4.7-5.4) with marked regional differences; there was a higher seroprevalence in the central area of the country $(11.3 \%)$, where Madrid is located and in the province of Barcelona (7.0\%), the latter closely communicated with Andorra.

The decrease in seroprevalence between the two surveys was an unexpected finding. This could be due to the decrease of IgM over the study period. Given that the majority of patients were asymptomatic and IgM peak declined early after infection, we could have undetectable levels in the second survey with rapid tests. ${ }^{23-25}$ In those cases, a more sensitive and quantitative test would be needed, but it was not within the scope of our study. We found no differences in seroprevalence between males and females, in line 
with other studies. ${ }^{11,12,17}$ Remarkably, the seroprevalence in the 10-19 years age group was one of the highest, and the age range between 2-9 presented a seroprevalence similar to the other age groups. These findings were different to other studies where seroprevalence in children was lower than in older age-groups. A potential explanation for these results could be the fact that one of the first outbreak foci detected in Andorra occurred within schools, therefore children were one of the first population groups to be affected. The fact that children and adolescents share common spaces and participate in leisure activities in groups could have facilitated this spread in the family nucleus and over the country, albeit in an asymptomatic way. Likewise, another group with high prevalence was people over 80 years, as expected and reported by other studies. ${ }^{11,15}$ The high mortality rate in this age group requires more attention and reinforced strategies to protect and treat this vulnerable high-risk group. ${ }^{28}$

Most participants with detectable SARS-CoV-2 antibodies were asymptomatic. Even in groups with high seroprevalence such as seasonal workers or students, the proportion of symptomatic cases was also very low. As expected, we found a higher prevalence in participants reporting having symptoms related with COVID-19 prior to the first survey, probably because the first survey was closer to the peak of cases.

Seasonal workers presented higher seroprevalence than the general population, even higher than health workers where we could have expected the highest seroprevalence. Although most seasonal workers work in outdoor spaces, they tend to interact with many people every day as well as to share common spaces, with many of them living in shared houses or dormitories which might have facilitated the spread of the virus. Although some studies show high seroprevalence among health care workers, ${ }^{31}$ we observed a seroprevalence similar than that of the general population and even lower than other groups such as students. Health care workers used personal protective equipment in the workplace early, and were closely followed-up, with rapid establishment of quarantines if a close interaction with a contact was ascertained. We found that larger households presented higher seroprevalence than smaller familiar nuclei. Prior studies have noted significant transmission of SARS-CoV-2 in households, highlighting the importance of quarantining index patients at home to prevent SARS-Co-2 transmission within households. ${ }^{32,33}$

One of the strengths of this study is the universality of testing, which includes over $93 \%$ of the inhabitants in Andorra. Unlike other published studies where samples are randomly selected, our selection bias is minimal and can give reliable information at the population history of SARS-CoV- 2 infection. The study was conducted within a short period thanks to voluntary citizen participation. This strategy can serve as a model for other countries aiming at conducting mass serological screening. Another key strength of the study was the execution of two cross sectional surveys. We adopted this approach to minimize human error, to increase test sensitivity, to account for seroconversion in people that were infected in the first survey and to minimize inconclusive results in either survey.

The study also had several limitations. First, the quality of data collection can be variable, because they were collected by volunteers, and during a short time per participant. In order to prioritize testing speed, it was decided to conduct a short survey, thus the variety of risk factors analyzed is limited. Second, 
symptoms were collected as self-reported symptoms. It could potentially provide inaccurate information about what the symptoms were, and if they were correctly attributed to COVID-19 as well as their severity. Third, we were unable to correctly identify around 3,000 inhabitants by census number, thus we were unable to include them in the household level analysis. Likewise, the exclusion of children $<2$ years of age precludes the generalization of the conclusions of this study to that age group. Lastly, the way we estimated overall seroprevalence (positive antibodies in any of the survey) maximizes the sensitivity of the test and minimizes specificity. Given that the seroprevalence of infection in the Andorran population was high and the specificity of the test was very high (98-99\%), we believe the proportion of false positive results, although certainly present, was small and would not affect the conclusions of the study.

In conclusion, this mass serological survey identified the immunological exposure of SARS-CoV-2 in the Andorran population. Detection of new cases of infections allowed for adequate isolation and tracing, preventing the spread of the virus at a time of relaxation of containment measures. The analysis contributed to identify high-risk groups and infection hotspots, such as temporary workers, and ski related areas respectively. These findings should be addressed in future policies of this highly touristic setting.

\section{Acknowledgements}

We thank the Government of the Principality of Andorra for its support and its financial contribution for the acquisition of medical equipment, supplies and the essential tools, the Health Department for its guidance, and the Foundation for the Innovation and Research Actuatech for performing the study and management of the entire data, Nil De Celis, Carlos Cebrecos. We thank FIND and the ISGlobal personnel for their support in the evaluation of the RDT, Ruth Aguilar, Alfons Jiménez, Diana Barrios, Laura Puyol and Rebeca Santano; and Francisco Carmona-Torre and Gabriel Reina at UNAV for positive COVID-19 samples. We thank Joan Oliva for his help with language correction.

We are grateful to the honorables municipalities of Canillo, Encamp, Ordino, La Massana, Andorra la Vella, Sant Julià de Lòria and Escaldes-Engordany; the Andorran Red Cross and civil protection for their assistance in the operational execution of the screening and management of volunteers. We thank all the volunteers for their participation and the entire population, making it possible to screen $90 \%$ of the country.

\section{References}

1. Wang C, Horby PW, Hayden FG, Gao GF. A novel coronavirus outbreak of global health concern. Lancet. 2020;395(10223):470-473. doi:10.1016/S0140-6736(20)30185-9

2. Practice BB. Coronavirus disease 2019. World Health Organ. 2020;2019(April):2633. doi:10.1001/jama.2020.2633

3. Gudbjartsson DF, Helgason A, Jonsson H, et al. Spread of SARS-CoV-2 in the Icelandic Population. N Engl J Med. April 2020:NEJMoa2006100. doi:10.1056/NEJMoa2006100 
4. Hellewell J, Abbott S, Gimma A, et al. Feasibility of controlling COVID-19 outbreaks by isolation of cases and contacts. Lancet Glob Heal. 2020;8(4):e488-e496. doi:10.1016/S2214-109X(20)30074-7

5. Pan A, Liu L, Wang C, et al. Association of Public Health Interventions with the Epidemiology of the COVID-19 Outbreak in Wuhan, China. JAMA - J Am Med Assoc. 2020;02115(19):1915-1923. doi:10.1001/jama.2020.6130

6. Ebrahim SH, Ahmed QA, Gozzer E, Schlagenhauf P, Memish ZA. Covid-19 and community mitigation strategies in a pandemic. BMJ. 2020;368:m1066. Published 2020 Mar 17. doi:10.1136/bmj.m1066

7. Zhao J, Yuan Q, Wang H, et al. Antibody responses to SARS-CoV-2 in patients of novel coronavirus disease 2019. Clin Infect Dis. March 2020. doi:10.1093/cid/ciaa344

8. Okba NMA, Müller MA, Li W, et al. Severe Acute Respiratory Syndrome Coronavirus 2-Specific Antibody Responses in Coronavirus Disease 2019 Patients. Emerg Infect Dis. 2020;26(7). doi:10.3201/eid2607.200841

9. Kissler SM, Tedijanto C, Goldstein E, Grad YH, Lipsitch M. Projecting the transmission dynamics of SARS-CoV-2 through the postpandemic period. Science. 2020;368(6493):860-868. doi:10.1126/science.abb5793

10. https://www.govern.ad/coronavirus

11. Pollán M, Pérez-Gómez B, Pastor-Barriuso R, et al. Prevalence of SARS-CoV-2 in Spain (ENE-COVID): a nationwide, population-based seroepidemiological study. Lancet (London, England). July 2020. doi:10.1016/S0140-6736(20)31483-5.

12. Xu X, Sun J, Nie S, et al. Seroprevalence of immunoglobulin M and $G$ antibodies against SARS-CoV-2 in China. Nat Med. 2020. doi:10.1038/s41591-020-0949-6

13. Sood N, Simon P, Ebner P, et al. Seroprevalence of SARS-CoV-2-Specific Antibodies among Adults in Los Angeles County, California, on April 10-11, 2020. JAMA - J Am Med Assoc. 2020;323(23):2425. doi:10.1001/jama.2020.8279

14. Bendavid E, Mulaney B, Sood N, et al. COVID-19 Antibody Seroprevalence in Santa Clara County, California. medRxiv. 2020:2020.04.14.20062463. doi:10.1101/2020.04.14.20062463

15. Stringhini S, Wisniak A, Piumatti G, et al. Seroprevalence of anti-SARS-CoV-2 IgG antibodies in Geneva, Switzerland (SEROCoV-POP): a population-based study. www.thelancet.com. 2020;396. doi:10.1016/S0140-6736(20)31304-0

16. Salje H, Kiem CT, Lefrancq N, et al. Estimating the burden of SARS-CoV-2 in France. Science 2020; published online May 13. https://doi.org/10.1126/science.abc3517

17. Snoeck CJ, Vaillant M, Abdelrahman T, et al. Prevalence of SARS-CoV-2 infection in the Luxembourgish population: the CON-VINCE study. medRxiv 2020; published online May 18. https://doi.org/10.1101/2020.05.11.20092916 (preprint).

18. Gudbjartsson DF, Norddahl GL, Melsted P, et al. Humoral Immune Response to SARS-CoV-2 in Iceland [published online ahead of print, 2020 Sep 1]. N Engl J Med. 2020;NEJMoa2026116.

doi:10.1056/NEJMoa2026116 
19. Hallal PC, Hartwig FP, Horta BL, et al. SARS-CoV-2 antibody prevalence in Brazil: results from two successive nationwide serological household surveys [published online ahead of print, 2020 Sep 23]. Lancet Glob Health. 2020;S2214-109X(20)30387-9. doi:10.1016/S2214-109X(20)30387-9

20. Murhekar MV, Bhatnagar T, Selvaraju S, et al. Prevalence of SARS-CoV-2 infection in India: Findings from the national serosurvey, May-June 2020. Indian J Med Res. 2020;152(1 \& 2):48-60. doi:10.4103/ijmr.IJMR_3290_20

21. Anand S, Montez-Rath M, Han J, et al. Prevalence of SARS-CoV-2 antibodies in a large nationwide sample of patients on dialysis in the USA: a cross-sectional study [published online ahead of print, 2020 Sep 25]. Lancet. 2020;396(10259):1335-1344. doi:10.1016/S0140-6736(20)32009-2

22. Department of Statistics of the Government of Andorra (https://www.estadistica.ad/serveiestudis/web/index.asp?lang=2).

23. Moncunill G, Mayor A, Santano R, et al. SARS-CoV-2 seroprevalence and antibody kinetics among health care workers in a Spanish hospital after three months of follow-up. XXXXX

24. Huang AT, Garcia-Carreras B, Hitchings MDT, et al. A systematic review of antibody mediated immunity to coronaviruses: antibody kinetics, correlates of protection, and association of antibody responses with severity of disease. Preprint. medRxiv. 2020;2020.04.14.20065771. Published 2020 Apr 17. doi:10.1101/2020.04.14.20065771

25. Siracusano G, Pastori C, Lopalco L. Humoral Immune Responses in COVID-19 Patients: A Window on the State of the Art. Front Immunol. 2020;11:1049. Published 2020 May 15. doi:10.3389/fimmu.2020.01049

26. Bunyavanich S, Do A, Vicencio A. Nasal gene expression of angiotensin-converting enzyme 2 in children and adults. JAMA 2020; published online May 20. https://doi.org/10.1001/jama.2020.8707

27. Braun J, Loyal L, Frentsch M, et al. SARS-CoV-2-reactive T cells in healthy donors and patients with COVID-19 [published online ahead of print, $2020 \mathrm{Jul}$ 29]. Nature. 2020;10.1038/s41586-020-2598-9. doi:10.1038/s41586-020-2598-9

28. Eva Heras, Pablo Garibaldi, Maite Boix et al. COVID-19 mortality risk factors in older people in a longterm care center, 02 September 2020, PREPRINT (Version 1) available at Research Square [+https://doi.org/10.21203/rs.3.rs-70219/v1+]

29. Ger Rijkers, Jean-Luc Murk, Bas Wintermans, et al. Differences in antibody kinetics and functionality between severe and mild SARS-CoV-2 infections. medRxiv 2020.06.09.20122036; doi: https://doi.org/10.1101/2020.06.09.20122036

30. Mateus J, Grifoni A, Tarke A, et al. Selective and cross-reactive SARS-CoV-2 T cell epitopes in unexposed humans [published online ahead of print, 2020 Aug 4]. Science. 2020;eabd3871. doi:10.1126/science.abd3871

31. Garcia-Basteiro AL, Moncunill G, Tortajada M, et al. Seroprevalence of antibodies against SARS-CoV2 among health care workers in a large Spanish reference hospital. medRxiv 2020; published online May 2. https://doi.org/10.1101/2020.04.27.20082289 
32. Li W, Zhang B, Lu J, et al. The characteristics of household transmission of COVID-19. Clin Infect Dis 2020; published online April 17. https://doi.org/10.1093/cid/ciaa450.

33. Jing Q-L, Liu M-J, Yuan J, Zhang Z-B, Zhang A-R, Dean NE, et al. Household Secondary Attack Rate of COVID-19 and Associated Determinants. medRxiv. 2020:2020.04.11.20056010.

\section{Tables}

Table 1. Baseline demographic characteristics

\begin{tabular}{|c|c|}
\hline & $\begin{array}{l}\text { Number of participants } \\
\qquad(n=63,992)\end{array}$ \\
\hline \multicolumn{2}{|l|}{ Sex } \\
\hline Female & $31,471(49.4 \%)$ \\
\hline Male & $32,204(50.6 \%)$ \\
\hline \multicolumn{2}{|l|}{ Age, years (SD) } \\
\hline $02-9$ & $4,312(7.0 \%)$ \\
\hline $\begin{array}{l}10-19 \\
20-29\end{array}$ & $\begin{array}{l}6,669(10.8 \%) \\
7,703(12.5 \%)\end{array}$ \\
\hline $30-39$ & $9,798(15.9 \%)$ \\
\hline $40-49$ & $12,049(19.5 \%)$ \\
\hline $50-59$ & $10,506(17.0 \%)$ \\
\hline $60-69$ & $6,164(10.0 \%)$ \\
\hline 70-79 & $3,033(4.9 \%)$ \\
\hline $80-89$ & $1,241(2.0 \%)$ \\
\hline$\geq 90$ & $265(0.4 \%)$ \\
\hline \multicolumn{2}{|l|}{ Occupational Status } \\
\hline Student & $12,290(17.7 \%)$ \\
\hline Seasonal worker & $2,885(4.0 \%)$ \\
\hline Health care worker & $2,167(3.1 \%)$ \\
\hline Others & $52,993(75.2 \%)$ \\
\hline \multicolumn{2}{|c|}{ Self-reported Symptoms } \\
\hline Before first survey & $1,746(2.6 \%)$ \\
\hline At time of survey & $226(0.3 \%)$ \\
\hline \multicolumn{2}{|l|}{ Parish } \\
\hline Andorra la Vella & $21,102(29.0 \%)$ \\
\hline Canillo & 4,729 (6.5\%) \\
\hline Encamp & $11,222(15.4 \%)$ \\
\hline Escaldes-Engordany & $13,347(18.3 \%)$ \\
\hline La Massana & $9,200(12.6 \%)$ \\
\hline Ordino & $4,330(5.9 \%)$ \\
\hline Sant Julia de Lòria & $8,863(12.2 \%)$ \\
\hline
\end{tabular}


*Percentages may vary due to missing data (due to lack of completion of the questionnaire) in different variables.

Table 2. Seroprevalence of SARS-Cov2 by general characteristics

\begin{tabular}{|c|c|c|c|}
\hline & $\begin{array}{c}\text { Seroprevalence } \\
\text { First survey }\end{array}$ & $\begin{array}{l}\text { Seroprevalence } \\
\text { Second survey }\end{array}$ & Overall seroprevalence \\
\hline $\begin{array}{l}\text { Overall } \\
\text { Sex }\end{array}$ & $6,816(9.7 \%)$ & $5,433(8.5 \%)$ & $8,032(11.0 \%)$ \\
\hline Female & $2,945(9.7 \%)$ & 2,414 (8.6\%) & $3,490(11.4 \%)$ \\
\hline Male & $2,931(9.4 \%)$ & $2,348(8.3 \%)$ & $3,521(11.3 \%)$ \\
\hline \multicolumn{4}{|l|}{ Age, years (\%) } \\
\hline $2-9$ & $325(7.9 \%)$ & 239 (7.3\%) & $447(10.9 \%)$ \\
\hline 10-19 & 626 (9.6\%) & 601 (9.7\%) & 889 (13.7\%) \\
\hline $20-29$ & $577(7.9 \%)$ & $423(6.7 \%)$ & $675(9.2 \%)$ \\
\hline $30-39$ & $751(7.9 \%)$ & $572(6.7 \%)$ & $899(9.5 \%)$ \\
\hline $40-49$ & $1,003(8.6 \%)$ & $894(8.1 \%)$ & $1,287(11.0 \%)$ \\
\hline $50-59$ & $1,213(11.9 \%)$ & $989(10.3 \%)$ & $1,396(13.6 \%)$ \\
\hline $60-69$ & $672(11.3 \%)$ & $536(9.5 \%)$ & $767(12.8 \%)$ \\
\hline 70-79 & $336(11.6 \%)$ & $267(9.6 \%)$ & $381(13.1 \%)$ \\
\hline $80-89$ & $138(11.8 \%)$ & $133(12.1 \%)$ & $162(13.8 \%)$ \\
\hline$\geq 90$ & $43(16.8 \%)$ & $33(14.6 \%)$ & $39(15.2 \%)$ \\
\hline \multicolumn{4}{|l|}{ Occupational status } \\
\hline Student & $1,104(9.1 \%)$ & $959(8.5 \%)$ & $1,507(12.4 \%)$ \\
\hline Seasonal worker & $358(13.3 \%)$ & $188(11.2 \%)$ & $288(10.7 \%)$ \\
\hline Health care worker & $227(10.6 \%)$ & $176(9.9 \%)$ & $222(10.4 \%)$ \\
\hline $\begin{array}{l}\text { Other jobs } \\
\text { Self-reported Symptoms }\end{array}$ & $4,988(9.5 \%)$ & $3,993(8.3 \%)$ & $5,888(11.2 \%)$ \\
\hline Symptoms at test moment & $34(15 \%)$ & $53(7.8 \%)$ & \\
\hline Symptoms before test & $313(17.9 \%)$ & $48(27.4 \%)$ & \\
\hline $\begin{array}{l}\text { No symptoms } \\
\text { Parish }\end{array}$ & $6,042(9.3 \%)$ & $4,982(8.4 \%)$ & \\
\hline Andorra la Vella & $1,502(7.4 \%)$ & $1,228(6.7 \%)$ & $1,699(8.1 \%)$ \\
\hline Canillo & $429(9.7 \%)$ & $303(8.2 \%)$ & $457(9.7 \%)$ \\
\hline Encamp & $919(8.5 \%)$ & $657(6.7 \%)$ & $970(8.6 \%)$ \\
\hline Escaldes -Engordany & $1,331(10.2 \%)$ & $955(8.1 \%)$ & $1,527(11.4 \%)$ \\
\hline La Massana & $1,163(13.2 \%)$ & $1,145(14.1 \%)$ & $1,636(17.8 \%)$ \\
\hline Ordino & $402(9.6 \%)$ & $360(9.4 \%)$ & $482(11.1 \%)$ \\
\hline Sant Julià de Lòria & $1,038(12.1 \%)$ & $774(9.6 \%)$ & $1,255(14.2 \%)$ \\
\hline
\end{tabular}

*Percentages may vary due to missing cases in different groups.

** Overall seroprevalence analysis we only used participants who were part of at least one survey 
Table 3. Univariable and multivariable analysis 


\begin{tabular}{|c|c|c|c|c|c|c|c|c|c|c|}
\hline Variable & & $n$ & Seroprevalence & $\begin{array}{c}\mathrm{p}- \\
\text { value }\end{array}$ & $\begin{array}{l}\text { Odds } \\
\text { Ratio }\end{array}$ & $95 \% \mathrm{Cl}$ & $\begin{array}{c}\mathrm{p}- \\
\text { value }\end{array}$ & $\begin{array}{l}\text { Odds } \\
\text { Ratio }\end{array}$ & $95 \% \mathrm{Cl}$ & $\begin{array}{c}\text { p- } \\
\text { value }\end{array}$ \\
\hline \multicolumn{11}{|l|}{ Sex } \\
\hline Female & & 27858 & 3490 (12.5\%) & 0.7563 & 1.00 & & & & & \\
\hline Male & & 28301 & 3521 (12.4\%) & & 0.99 & $(0.94 ; .1 .04)$ & & & & \\
\hline \multicolumn{11}{|l|}{ Age (years) } \\
\hline $2-9$ & & 3899 & $447(11.5 \%)$ & & 1.00 & & & & & \\
\hline $10-19$ & & 6196 & $889(14.3 \%)$ & & 1.29 & $(1.15 ; 1.46)$ & & & & \\
\hline $20-29$ & & 6305 & $675(10.7 \%)$ & & 0.93 & $(0.82 ; 1.05)$ & & & & \\
\hline $30-39$ & & 8587 & $899(10.5 \%)$ & & 0.90 & $(0.80 ; 1.02)$ & & & & \\
\hline $40-49$ & & 10985 & $1287(11.7 \%)$ & $\begin{array}{c}< \\
0.0001\end{array}$ & 1.02 & $(0.91 ; 1.15)$ & $\begin{array}{c}< \\
0.0001\end{array}$ & & & \\
\hline $50-59$ & & 9560 & $1396(14.6 \%)$ & & 1.32 & $(1.18 ; 1.48)$ & & & & \\
\hline 60-69 & & 5655 & $767(13.6 \%)$ & & 1.21 & $(1.07 ; 1.37)$ & & & & \\
\hline 70-79 & & 2776 & $381(13.7 \%)$ & & 1.23 & $(1.06 ; 1.42)$ & & & & \\
\hline $80-89$ & & 1093 & $162(14.8 \%)$ & & 1.34 & $(1.11 ; 1.63)$ & & & & \\
\hline$\geq 90$ & & 226 & $39(17.3 \%)$ & & 1.61 & $(1.13 ; 2.31)$ & & & & \\
\hline \multicolumn{11}{|l|}{ Symptoms } \\
\hline \multirow[t]{2}{*}{ Symptoms first survey } & no & 58781 & 7261 (32.6\%) & & 1.00 & & & & & \\
\hline & yes & 1667 & $338(20.3 \%)$ & $\begin{array}{c}< \\
0.0001\end{array}$ & 1.80 & $(1.60 ; 2.04)$ & $\begin{array}{c}< \\
0.0001\end{array}$ & 1.99 & $\begin{array}{l}(1.71 ; \\
2.31)\end{array}$ & $\begin{array}{c}< \\
0.0001\end{array}$ \\
\hline \multirow{2}{*}{$\begin{array}{l}\text { Symptoms second } \\
\text { survey }\end{array}$} & no & 59253 & $7463(12.59 \%)$ & & 1.00 & & & & & \\
\hline & yes & 836 & $140(16.7 \%)$ & 0.0003 & 1.40 & $(1.16 ; 1.68)$ & 0.0004 & & & \\
\hline \multicolumn{11}{|l|}{$\begin{array}{l}\text { Occupational } \\
\text { status }\end{array}$} \\
\hline \multirow[t]{2}{*}{ Student } & no & 50918 & $6318(12.4 \%)$ & & 1.00 & & & & & \\
\hline & yes & 11296 & 1507 (13.3\%) & 0.0068 & 1.09 & $(1.02 ; 1.15)$ & 0.0068 & 1.51 & $\begin{array}{l}(1.37 ; \\
1.67)\end{array}$ & $\begin{array}{c}< \\
0.0001\end{array}$ \\
\hline \multirow[t]{2}{*}{ Seasonal worker } & no & 61864 & 7715 (12.4\%) & & 1.00 & & & & & \\
\hline & yes & 1681 & $288(17.1 \%)$ & $\begin{array}{c}< \\
0.0001\end{array}$ & 1.45 & $(1.28 ; 1.65)$ & $\begin{array}{c}< \\
0.0001\end{array}$ & 1.87 & $\begin{array}{l}(1.57 \\
2.23)\end{array}$ & $\begin{array}{c}< \\
0.0001\end{array}$ \\
\hline \multirow[t]{2}{*}{ Health care worker } & no & 60985 & $7670(12.5 \%)$ & & 1.00 & & & & & \\
\hline & yes & 1771 & $222(12.5 \%)$ & 0.9585 & 1.00 & $(0.86 ; 1.15)$ & 0.9586 & & & \\
\hline \multicolumn{11}{|l|}{ Parish } \\
\hline Andorra la vella & & 18277 & $1699(9.3 \%)$ & & 1.00 & & & 1.00 & & \\
\hline Canillo & & 3708 & $457(12.3 \%)$ & & 1.37 & $(1.23 ; 1.53)$ & & 1.15 & $\begin{array}{l}(1.01 \\
1.32)\end{array}$ & \\
\hline Encamp & & 9801 & $970(9.9 \%)$ & & 1.07 & $(0.99 ; 1.16)$ & & 1.10 & $\begin{array}{l}(0.99 \\
1.22)\end{array}$ & \\
\hline Escaldes-Engordany & & 11804 & $1527(12.9 \%)$ & $\begin{array}{c}< \\
0.0001\end{array}$ & 1.45 & $(1.35 ; 1.56)$ & $\begin{array}{c}< \\
0.0001\end{array}$ & 1.44 & $\begin{array}{l}(1.32 ; \\
1.57)\end{array}$ & $\begin{array}{c}< \\
0.0001\end{array}$ \\
\hline La Massana & & 8108 & $1636(20.2 \%)$ & & 2.47 & $(2.29 ; 2.66)$ & & 2.65 & $\begin{array}{l}(2.43 ; \\
2.89)\end{array}$ & \\
\hline Ordino & & 3807 & 481 (12.6\%) & & 1.41 & $(1.27 ; 1.57)$ & & 1.47 & $\begin{array}{l}(1.30 \\
1.67)\end{array}$ & \\
\hline Sant Julià & & 8021 & $1255(15.6 \%)$ & & 1.81 & $(1.67 ; 1.96)$ & & 1.84 & $\begin{array}{l}(1.68 \\
2.02)\end{array}$ & \\
\hline
\end{tabular}




\section{Table 4. Seroprevalence by household size}

\begin{tabular}{|c|c|c|c|c|}
\hline $\begin{array}{l}\text { Number of people } \\
\text { household }\end{array}$ & $\begin{array}{c}\text { All members negative in } \\
\text { both surveys }\end{array}$ & $\begin{array}{c}\text { All negative at first survey, some } \\
\text { positive at end }\end{array}$ & $\begin{array}{l}\text { Some positive at First survey, all } \\
\text { negative at end }\end{array}$ & $\begin{array}{l}\text { Someone positive in } \\
\text { both surveys }\end{array}$ \\
\hline Small (1/2 people) & 17027 (85.3\%) & $696(3.5 \%)$ & $960(4.8 \%)$ & $1278(6.4 \%)$ \\
\hline $\begin{array}{l}\text { Medium }(3 / 4 / 5 \\
\text { people) }\end{array}$ & $5870(70.7 \%)$ & $590(7.1 \%)$ & $751(9.0 \%)$ & 1097 (13.2\%) \\
\hline $\begin{array}{l}\text { Large ( } 6 \text { or more } \\
\text { people) }\end{array}$ & $71(55.5 \%)$ & $18(14.1 \%)$ & $10(7.8 \%)$ & $29(22.7 \%)$ \\
\hline
\end{tabular}

\section{Figures}

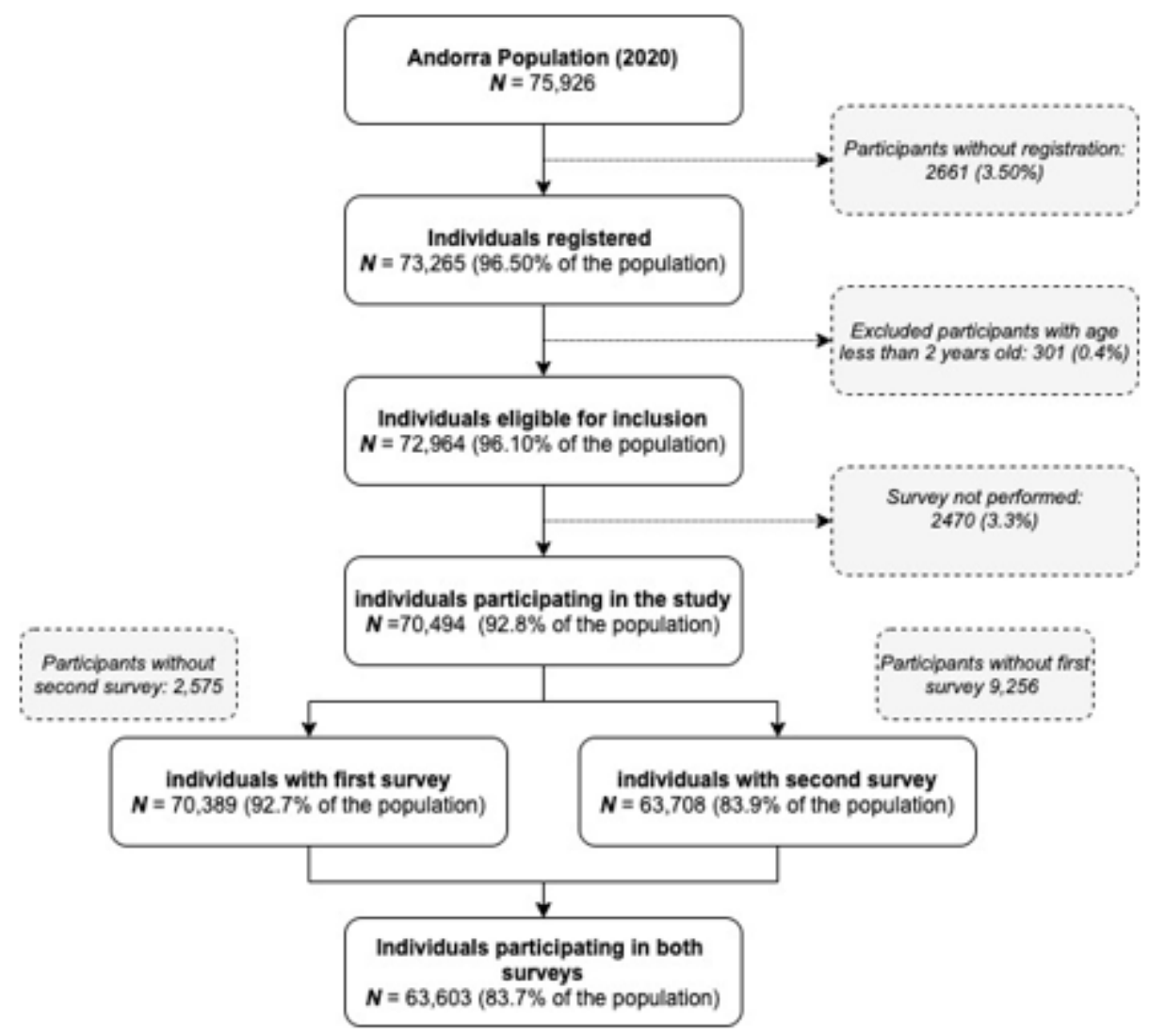

Figure 1

Flow Chart 


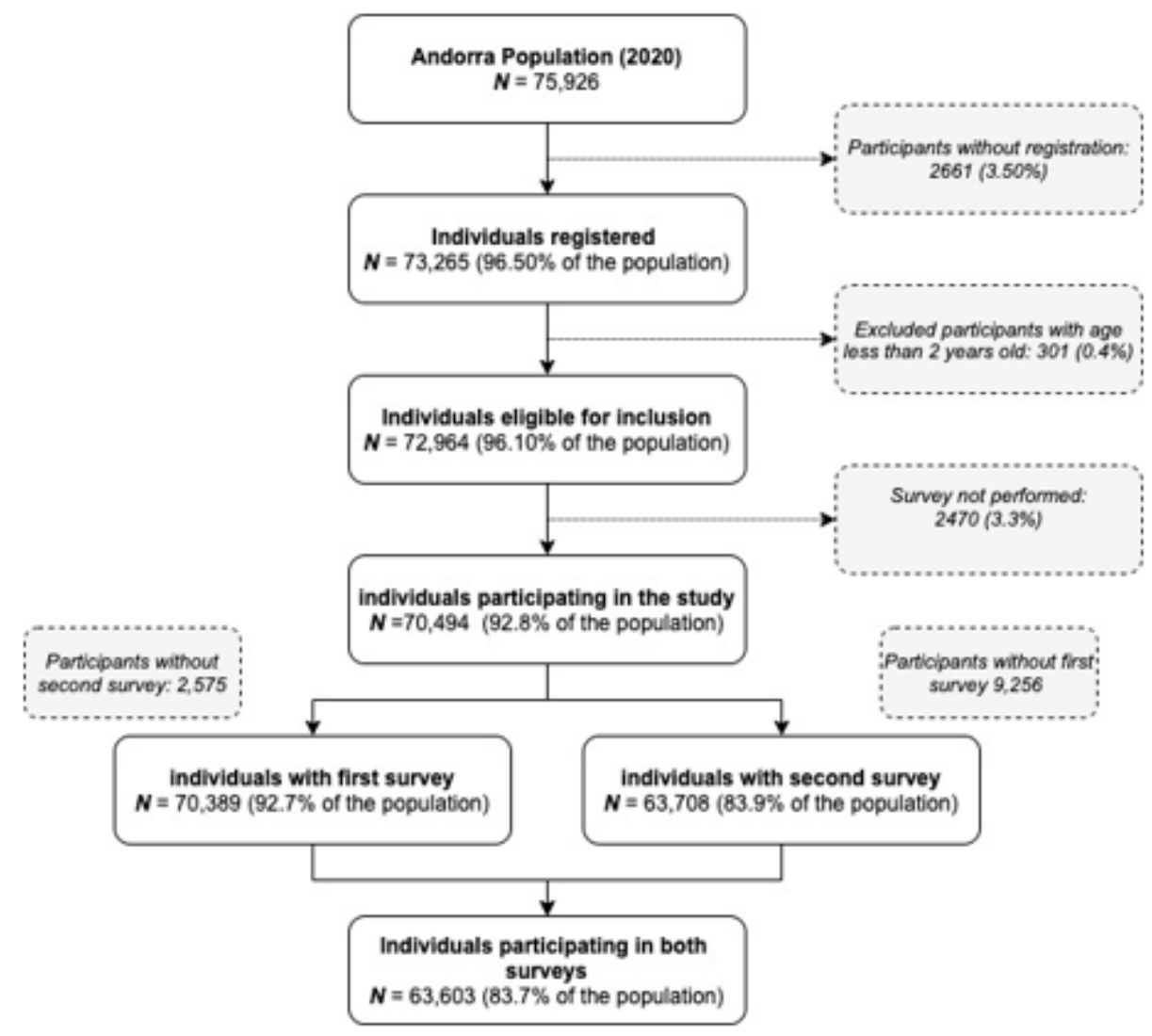

\section{Figure 1}

Flow Chart 

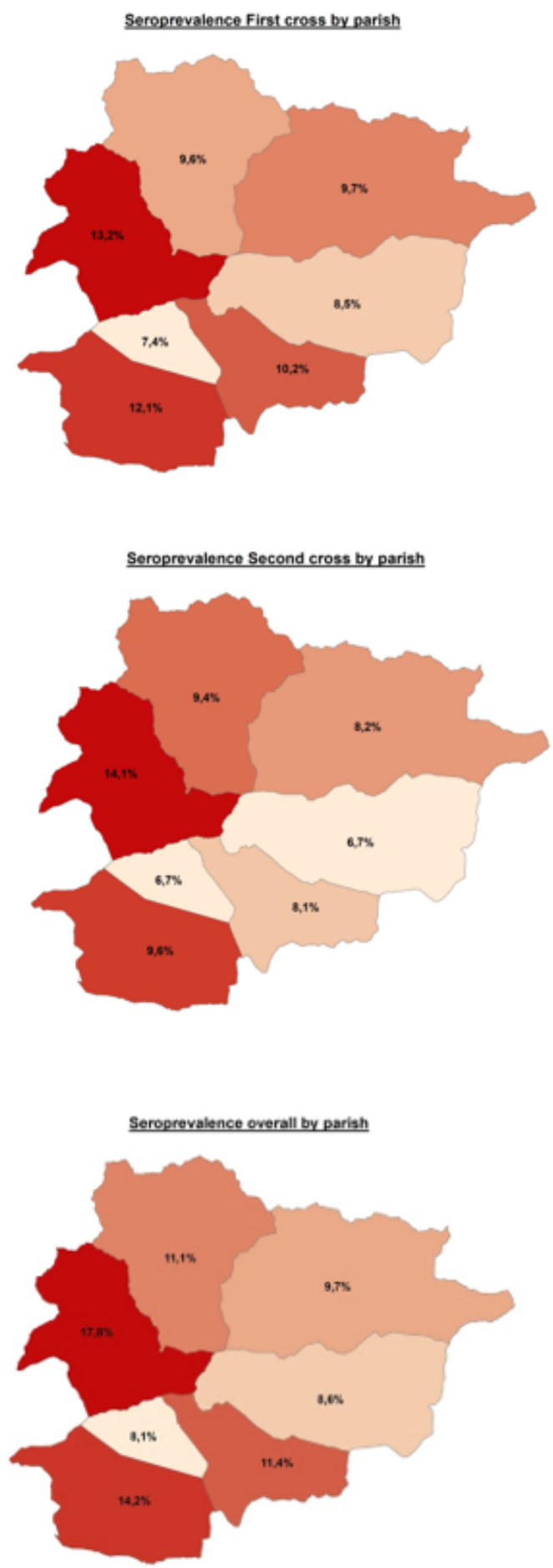

Figure 2

Seroprevalence by parish 

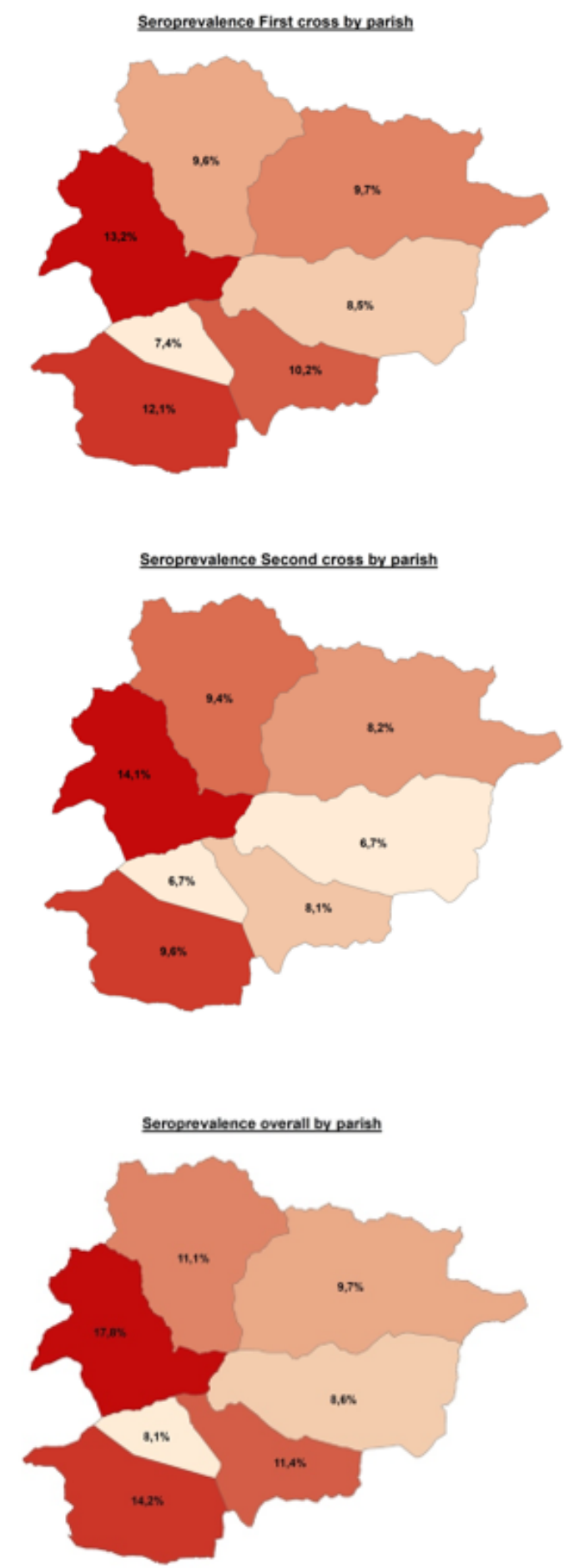

Figure 2

Seroprevalence by parish

\section{Supplementary Files}

This is a list of supplementary files associated with this preprint. Click to download. 
- SupplementaryAppendixNatcommMassserologicalscreening.docx

- SupplementaryAppendixNatcommMassserologicalscreening.docx 